\title{
Polymers of Natural Origin in Advanced Study of Research: Fabrication of Pharmaceutical Delivery Device
}

\author{
Roy $\mathrm{H}^{1 *}$, Nayak $\mathrm{BS}^{2}$ and Peter HPL ${ }^{3}$ \\ ${ }^{1}$ Department of Pharmacy, Biju Patnaik University of Technology, Rourkela, India \\ ${ }^{2}$ Department of Pharmaceutical Technology, Jeypore College of Pharmacy, India \\ ${ }^{3}$ Research Scholar, Annamalai University, India
}

Submission: March 15, 2017; Published: May 03, 2017

*Corresponding author: Hare Krishna Roy, Division of Pharmaceutical Technology, Nirmala College of Pharmacy, Mangalagiri, India,

Tel: 7382030060; Email: hareroy@gmail.com

\begin{abstract}
Polymers assume a noteworthy part in the improvement of medication conveyance innovation by arrival of two sorts of medications like hydrophilic and hydrophobic. In a synchronized way and consistent arrival of plans over broadened periods. There are various favorable circumstances of polymers going about as a dormant transporter. Nonetheless they have their own particular impediments, for example, the polymers regularly delivers undesirable and undesirable symptom, immunogenic enactment potential, should have been surgery after they discharge the medication at the focused in the vicinity and cost additionally a potential element. In such respects, Natural polymers turned out to be the better option limiting the risk of disappointment of medication conveyance framework.
\end{abstract}

Keywords: Polymers; Hydrophillic; Natural; Immunogenic

\section{Introduction}

Polymers are substances whose particles have high molar masses and compacted of a substantial number of rehashing units. Polymers can shape particles of strong dose frame and furthermore can change the stream property of fluid dose shape. Polymers are the foundation of pharmaceutical medication conveyance frameworks. Polymers have been utilized as a critical instrument to control the medication discharge rate from the definition. They are likewise for the most part utilized as stabilizer, taste-production operator, and proactive specialist. Present day progresses in medication conveyance are currently predicated upon the levelheaded outline of polymers customized particular load and built to apply unmistakable organic capacities. Polymers are both normally happening and manufactured. Among normally happening polymers are proteins, starches, latex and cellulose. Manufactured polymers are created on an extensive scale and have a numerous properties and utilized. Two or three audit articles on normal gums are accessible in literary works. A portion of the surveys secured the compound structure, event and creation of exudate gums, their size and relative significance of the different players on the world market and concentrated on their application in sustenance and different regions. Because of the developing enthusiasm for the utilization of characteristic polymeric materials as pharmaceutical excipients, as exhibited by the quantity of distributed logical papers, it is hard to cover all that may be accessible in a solitary article. It is proposed in this survey to talk about the employments of normal polymers as excipients in pharmaceutical definitions. Particular specify is made of a portion of the normal items as of now being used as pharmaceutical excipients and those being looked into for this reason [1-4].

\section{Natural Polymeric Materials}

\section{Cellulose}

In higher plants, cellulose is a basic auxiliary part and speaks to the most plenteous natural polymer. Cellulose is a straight unbranched polysaccharide comprising of $\beta-1,4-$ connected D-glucose units and many parallel cellulose particles which frame crystalline small scale fibrils. The development of subsidiaries of cellulose is made conceivable by the hydroxyl moieties on the D-glucopyranose units of the cellulose polymer 
to give an assortment of subordinates. Cellulose subordinates can be made by etherification, esterification, cross-connecting or unite copolymerization. Etherification yields subsidiaries, for example, hydroxyl-propyl-methylcellulose and carboxyl-methylcellulose, while esterification brings about subordinates which incorporate cellulose nitrate, cellulose acetic acid derivation and cellulose acetic acid derivation phthalate. These subordinates have discovered application in layer controlled discharge frameworks, for example, enteric covering and the utilization of semi-penetrable layers in osmotic pump conveyance frameworks $[5,6]$.

\section{Pectins}

Pectins are non-starch, direct polysaccharides removed from the plant cell dividers. They are prevalently straight polymers of predominantly (1-4)-connected D-galacturonic corrosive buildups hindered by 1,2-connected L-Rhamnose deposits. Smaller scale particulate polymeric conveyance frameworks have been accounted for as a conceivable way to deal with enhance the low bioavailability attributes saw in standard ophthalmic vehicles [7].

\section{Gums and mucilages}

Gums are regular plant hydrocolloids that might be delegated anionic or nonionic polysaccharides or salts of polysaccharides. They are translucent, undefined substances more often than not delivered by plants as a defensive after damage. Gums, adhesive, pectins and celluloses are delegated substances that are buildups of pentoses and additionally hexoses. They have various applications as thickeners, emulsifiers, viscosifiers, sweeteners and so on in confectionary, and as covers and medication discharge modifiers in pharmaceutical measurements frames. Be that as it may, the vast majority of the gums in their putative shape are required in high fixations to effectively work as medication discharge modifiers in dose frames because of their high swellability/dissolvability at acidic pH. Henceforth, gums should be changed to adjust their physicochemical properties. For instance, the change of gums through derivatisation of useful gatherings, uniting with polymers, cross-connecting with particles and different methodologies and additionally the variables impacting these procedures in the quest for making them appropriate for altering the medication discharge properties of pharmaceutical dose frames [8,9].

\section{Alginates}

Alginates are characteristic polysaccharide polymers secluded from the cocoa ocean weed (Phaeophyceae). Alginic corrosive can be changed over into its salts, of which sodium alginate is the significant shape presently utilized. The scientists officially planned bio-cement sodium alginate microspheres of metoprolol tartarate for intranasal systemic conveyance were set up to dodge the principal pass impact, as an option treatment to infusion, and to acquire enhanced helpful viability in the treatment of hypertension and angina pectoris [10].

\section{Carageenans}

The carrageenans are sulphated marine hydrocolloids acquired by extraction from kelp of the class Rhodophyceae, spoke to by Chondruscrispus, Euchemaspinosum. Thinks about have demonstrated that the carrageenans are appropriate in the definition of controlled discharge tablets [11].

\section{Xanthan gum}

Xanthan gum, a complex microbial exopolysaccharide delivered from glucose aging by Xanthomonas campestrispv. Xanthan gum has been utilized as a part of an extensive variety of businesses including sustenance, oil recuperation, makeup and pharmaceutical ventures. This wide application is because of its prevalent rheological properties. It is utilized as stabilizer for emulsions and suspensions [12].

\section{Gellan gum}

Deacylated Gellan gum (Gellan) is an anionic microbial polysaccharide, emitted from Sphingomonas elodea, comprising of rehashing tetrasaccharide units of glucose, glucuronic corrosive and rhamnose buildups in a 2:1:1 proportion. The physical gelation properties make this polysaccharide appropriate as an organizing and gelling operator in sustenance businesses. Gellan is additionally misused in the field of altered arrival of bioactive atoms. Fluid arrangements of Gellan are utilized as in situ gelling frameworks, for the most part for ophthalmic readiness and for oral medication conveyance [13].

\section{Rosin}

Rosin is a low atomic weight (400Da) normal polymer got from the oleoresin of Pinussoxburghui, Pinuslongifolium and Pinustoeda. It has as parts abietic and pimaric acids. Rosin and its subsidiaries have delighted in developing parts in Pharmacy. They have been explored for microencapsulation, film-framing and covering properties, and as grid materials in tablets for managed and controlled discharge [14].

\section{Hakeagibbosa gum}

The muco cement and maintained discharge properties of the water-solvent gum acquired from Hakeagibbosa (hakea), for the detailing of buccal tablets. Level confronted tablets containing hakea were figured utilizing chlorpheniramine maleate (CPM) as a model medication had been explored [15].

\section{Chitosan}

Chitosan is a straight polysaccharide made out of arbitrarily appropriated $\beta$-(1-4) connected D-glucosamine and N-acetyl-Dglucosamine. It is made by treating shrimp and other shellfish shells with the soluble base, sodium hydroxide. It is likewise normally exhibit in a few microorganisms and growths, for example, yeast. Analysts are being attempted chitosan as base for arrangement of Micro particulate medication conveyance framework and gadgets [16]. 


\section{Global Journal of Pharmacy \& Pharmaceutical Sciences}

\section{Conclusion}

It can be concluded that, there a lot more research awareness should be promoted from primary label to the extent of deep study.

\section{References}

1. Roy H, Nayak BS (2017) Formulation and Design of Sustained Release Matrix Tablets of Lamivudine: Combination of Chitosan and HPMC. American Journal of Pharmacy and Health Research 5(2): 01-10.

2. Maneesh K, Gaurav S, Ravinder K, Kapil K, Paramjot k, et al. (2010) Applications of novel excipients in the allopathic and herbal formulations. J Chem Pharm Res 2(4): 851-860.

3. Miyoshi E, Takaya T, Nishinari K (1996) Rheological and thermal studies of gel-sol transition in Gellan gum aqueous solutions. Carbohydrate Polymer 30: 109-119.

4. Roy H, Nayak BS (2017) Formulation and Design of Microparticles based Drug Delivery System of Selective Anti-Retroviral Drug by Chitosan. Scholars academy journal of pharmacy 6(1): 34-39.

5. Matricardi P, Cencetti C, Ria R, Alhaique F, Coviello T (2009) Preparation and Characterization of Novel Gellan Gum Hydrogels Suitable for Modified Drug Release. Molecules 14(9): 3376-3391.

6. Roy Hk, Nayak BS (2017) Formulation and Design of Microparticulate Drug Delivery System of Lamivudine by Chitosan as Natural Polymer. Sch J App Med Sci 5(1D): 267-272.

7. Rana V, Rai P, Tiwary AK, Singh RS, Kennedy JF, et al. (2011) Modified gums: Approaches and applications in drug delivery. Carbohydrate Polymers 83: 1031-1047.

8. Roy H, Nayak BS (2017) Design and In-vitro Evaluation of Sustained Release Matrix Tablets of Zidovudine Hydrochloride: Combination
Of Natural Polymers. Journal of Medical Pharmaceutical and Allied Sciences 596-605.

9. Vajra VSP, Roy H, NL Prashanti, N Jyothi (2016) Polymers In Drug Delivery Technology, Types Of Polymers And Applications. Sch Acad J Pharm 5(7): 305-308

10. Miyazaki S, Aoyama H, Kawasaki N, Kubo W, Attwood D (1999) In-situ gelling Gellan formulations as vehicles for oral drug delivery. J control release 60(2-3): 287-295.

11. Jyothi N, Roy Hk, Prasanhti LN, priya VSV (2016) A Brief Review of Microparticle Drug Delivery System. World Journal of Pharmacy and Pharmaceutical Sciences 5(7): 701-712.

12. Roy Hk (2015) Formulation of Sustained Release Matrix Tablets of Metformin hydrochloride by Polyacrylate Polymer. Int J Pharma Res Health Sci 3(6): 900-906.

13. Roy H, Rao PV, Panda SK, Biswal AK, Parida KR, et al. (2014) Composite alginate hydrogel microparticulate delivery system of zidovudine hydrochloride based on counter ion induced aggregation. Int J Appl Basic Med Res 4(Suppl 1): S31-36.

14. Agnihotri SA, Jawalkar SS, Aminabhavi TM (2006) Controlled release of cephalexin through Gellan gum beads: Effect of formulation parameters on entrapment efficiency, size, and drug release. Eur J Pharm Biopharm 63(3): 249-261.

15. Mohamadnia Z, Zohuriaan MMJ, Kabiri K, Jamshidi A, Mobedi H (2008) Ionically crosslinked carrageenan-alginate hydrogel beads. J Biomater Sci Polym Ed 19(1): 47-59.

16. Rajinikanth PS, Sankar C, Mishra B (2003) Sodium alginate microspheres of metoprolol tartrate for intranasal systemic delivery: Development and evaluation. Drug Deliv 10(1): 21-28.

Your next submission with Juniper Publishers will reach you the below assets

- Quality Editorial service

- Swift Peer Review

- Reprints availability

- E-prints Service

- Manuscript Podcast for convenient understanding

- Global attainment for your research

- Manuscript accessibility in different formats

( Pdf, E-pub, Full Text, Audio)

- Unceasing customer service

Track the below URL for one-step submission https://juniperpublishers.com/online-submission.php 